\title{
Headsprout Early Reading for Specific Literacy Difficulty: A Comparison Study
}

\author{
Catherine Storey $^{1}$ (D) Claire McDowell ${ }^{2} \cdot$ Julian C. Leslie ${ }^{2}$
}

Published online: 18 June 2019

(C) The Author(s) 2019

\begin{abstract}
This study compared the efficacy of the Headsprout ${ }^{\odot}$ Early Reading (HER) program with SENCO-delivered supplementary literacy instruction. Participants were primary school children (aged 6-9) in receipt of free school meals and supplementary literacy instruction. Data were collected within their school setting. The treatment group received HER intervention, while the treatment as usual (TAU) group received SENCO-delivered intervention, inclusive of guided reading, paper-based phonics training and word recognition tasks. It was hypothesized that children in the HER intervention group would significantly outperform those in the TAU group on measures of word/non-word recognition and sentence reading over a 7-month period. Thirty-two pupils with specific literacy difficulty were randomized to either HER $(n=17)$ or TAU $(n=15)$. Literacy skills were assessed using the Phonics and Early Reading Assessment pre- and post-intervention. ANOVA and $t$ test analysis found that HER made significantly greater gains on measures of word/non-word recognition $[t(30)=7.55, p<0.001]$, sentence reading $[t(30)=3.33, p<0.05]$ and sight words $[t(30)=4.23, p<0.001]$ than the TAU group. This study is the first to demonstrate stronger outcomes for children receiving computer-aided instruction over SENCO-delivered literacy instruction in a Northern Irish School.
\end{abstract}

Keywords Reading instruction · Computer-assisted instruction · Headsprout · Emergent literacy $\cdot$ Literacy difficulty

Catherine Storey

c.storey@qub.ac.uk

Claire McDowell

ce.mcdowell@ulster.ac.uk

Julian C. Leslie

Jc.leslie@ulster.ac.uk

1 School of Social Sciences, Education and Social Work, Queens University Belfast, 69-71 University Street, Belfast BT71HL, Northern Ireland, UK

2 Ulster University, Cromore Road, Coleraine BT521SA, Co. Londonderry, Northern Ireland, UK 


\section{Introduction}

Recent findings in the UK from The Department for Education's "Effective Preschool, Primary and Secondary Education Project" (EPPSE-2014) show that children's life chances are shaped by family, home and school experiences. Effects of disadvantage in one or more of these environments emerge early and continue to shape later educational outcomes, posing risks to health and employment, and increasing the probability of criminal activity [McIntosh and Vignoles 2001; Northern Ireland Executive 2000]. Although it is not the only indicator, disadvantage is often identified by free school meals (FSM) entitlement. Schools in Northern Ireland (NI) have a higher percentage of FSM pupils than anywhere else in the UK. In addition, the Joseph Rowntree Foundation (2012) found that $30 \%$ of children in the most deprived fifth of schools in NI did not reach their expected level in English prior to leaving Primary School in comparison with $18 \%$ of all other schools. More recent NI statistics show that while the percentage of school leavers receiving FSM achieving level 2 in English and Mathematics has increased from $27.7 \%$ in $2007-2008$ to $41.3 \%$ in $2014-2015$; the percentage for those not entitled to FSM has also increased by the same proportion (PGCD 2016). Therefore, although educational outcomes are slowly improving for this population of children, the attainment gap is not closing.

Save the Children (2015) examined data from the Millennium Cohort Study and concluded that the effects of poor literacy at the age of 5 are likely to negatively impact on pupils' attainment at the end of primary school (11 years of age) and on into adult life. The report also indicated that pupils living in persistent poverty are twice as likely to score below average for language development and reading comprehension tests at the age of 11 compared to their peers who have not experienced persistent disadvantage.

The National Reading Panel report (2000) stressed the importance of teaching reading using a systematic phonics approach and identified the five key skills that are necessary to learn to read. These are phonemic awareness (the ability to recognize that sounds are made up of separate sounds called phonemes); reading phonics (understanding that letter combinations are linked to particular sounds); reading vocabulary (understanding that words have meaning); reading fluency (the ability to read quickly and accurately); and reading comprehension (the ability to understand what is read).

Research investigating remedial action for disadvantaged children confirms that explicit systematic phonological training is the fastest and most effective method of increasing word recognition and subsequently reading accuracy (Bradley and Bryant 1983; Hatcher et al. 1994; Johnston and Watson 2004; Lundberg et al. 1988). In an independent report to the Secretary of State for Children, Schools and Families, Rose (2009) stresses the danger of choosing ineffective interventions with no scientific support and also concludes that literacy difficulties should be targeted with interventions that systematically target phonological skills. However, if a teaching method is effective in improving a skill, but does not teach at a faster rate, children with literacy difficulties will always remain a 
step behind their peers. An effective intervention should therefore quicken the pace of learning in an attempt to narrow the attainment gap between those with literacy difficulties and their peers. Even though the importance of explicit, systematic teaching of phonics and phonological awareness is well established, many educators hold the belief that other strategies in current use, or that are recommended, have the support of an empirical evidence base relating to efficiency and effectiveness. Unfortunately, this is often not the case in education where interventions are implemented inconsistently and lack the experimental control necessary to state with confidence that a particular intervention is effective (Carter and Wheldall 2008).

A range of strategies are currently being used across schools in the UK and Ireland. Among these are the Aural-Read-Respond-Oral-Write (A.R.R.O.W) program (Lane 2010), Catch-Up Literacy (Clipson-Boyles 2000), Paired Reading (Morgan 1976) and Reading Recovery (Clay 1987). Despite being some of the most widely used supplementary literacy programs across the nation, these strategies do not adhere to the National Reading Panel's guidance that systematic phonics training is the most effective method of increasing literacy skills. Many of these approaches implement a whole-language instructive method whereby words are presented as whole pieces of language that should be acquired through repeated exposure, rather than through the identification of phonemes within words as suggested by the National Reading Panel's guidelines. Much of the description of the specific procedures for each intervention is not systematic and therefore lacks sufficient detail for replication which, in turn, is necessary to build an evidence-base. Teachers or teaching assistants use a variety of instructional methods as and when they encounter issues; thus, the approach to literacy instruction becomes eclectic in nature and difficult to replicate. Although procedural instructions for each of these programs put sufficient emphasis on the importance of reinforcement, little is known about error correction procedures used or data collection methods to track progress over time and make data-driven decisions. In order to be considered systematic, instruction should be based on the principles of setting clear learning outcomes, teaching that is individual to the learner and setting high-performance targets (typically 90\%) that learners must meet or repeat components until these criteria have been met. In addition, data should be collected on each response and corrective feedback should be delivered immediately (Layng et al. 2003; Storey et al. 2017).

The impact of technology in our society has in no small way affected the education system. The rapid development of technology has allowed and encouraged educators to adopt information and communication technologies (ICT) to support teaching and learning and in guiding children to be functional ICT users (Sedega et al. 2017). Karemaker et al. (2010) conducted a comparison study between a computer-assisted approach to literacy instruction and a traditional whole-language approach to instruction. The multimedia software "Oxford Reading Tree (ORT) for Clicker" was compared to a reading intervention using traditional ORT Big Books to compare gains in developing literacy skills and reading enjoyment for 17 struggling readers aged 5-6. The ORT Clicker automatically highlights each word being read in red as it is sounded out by a narrator on a smartboard. Six interactive activities followed on a laptop to reinforce the keywords used in each story: "words", 
"word practice", "sentences", "comprehension", "writing" and "make a book". The ORT Big Book intervention uses a larger printed text of the books read aloud by the teacher while a small group of children sit in a circle around the printed text. Significant gains in performance were found following both interventions, but significantly greater gains were found in written word recognition and enjoyment of reading following the Clicker than Big Book intervention (Karemaker et al. 2010).

Macaruso et al. (2006) found that "at-risk" students in two treatment groups receiving supplementary CAI phonics-based programs showed higher gains in posttest reading measures than a control group receiving only typical classroom-based instruction. More recently, Macaruso and Walker (2008) compared posttest reading measures of 94 children, aged 3-4 years old, enrolled in Kindergarten classes. They found that the treatment group who received CAI as a supplement to a normal classroom-based phonics reading curriculum significantly outperformed the control group on reading measures, particularly those that assessed phonological awareness skills. However, in a review of the available literature, Stetter and Hughes (2010) concluded that while computer-based programs offer students with learning disabilities, and reading difficulties, valuable support, the results of studies published between 1985 and 2009 show inconsistent results. They stated the need for further research evaluating the effectiveness of CAI with children at risk of reading failure.

The National Reading Panel (NRP 2000) has outlined the effectiveness of computer-assisted instruction (CAI). CAI is used to describe specific computer applications in education offered as independent activities or supplementary to general classroom instruction (Cotton 1991). When the computer is used in this way, Ornstein and Levine (1993) believed that it emphasizes practice and drill programs and is appropriate when subject matter needs to be mastered for practice of basic skills before advancing to higher levels of learning. This is synonymous with developing literacy skills; strong foundations in phonemic awareness must be cemented as reading tasks increase in difficulty when children progress through the school system (Lundberg et al. 1998). Singleton (2009) and Linehan et al. (2011) report that the use of computers increases student motivation by providing fast-paced, individualized lessons while offering students the ability to make numerous and different kinds of responses, not otherwise available through conventional teaching methods. The results of a summary of 59 CAI studies found that: (a) the use of CAI alongside conventional instruction produced greater results than conventional instruction alone; (b) students learn material faster with CAI than conventional instruction alone; (c) CAI is more beneficial for younger students (aged 5-11) than older students (postprimary, aged 11-18) and lower-achieving students than higher-achieving students; (d) students with specific learning difficulties achieve better results with CAI than with conventional instruction alone; and (e) student's enjoyment of CAI activities is a direct result of the delivery of immediate feedback.

One such CAI program showing promising results in emerging literature is Headsprout Early Reading ${ }^{\odot}$ (HER). Headsprout Early Reading is an engaging, internet-based reading program that aims to accelerate early reading skills in students in primary school grades (Layng et al. 2003). The program consists of 80 episodes (lessons), (with an additional 50 that target comprehension) each taking approximately 20-30 min to complete. Consistent with the principles of Behaviour 
Analysis and Direct Instruction (Watkins 1997), and aiming to teach "more in less time," Headsprout ${ }^{\odot}$, breaks the reading curriculum into clear systematic parts that are taught, via online lessons, in a specific order without assuming background knowledge. No stage is introduced without the previous learning objectives being mastered, and thus, decisions to progress to the next stage of the curriculum are data-driven (i.e., based on the child's performance). Lessons are designed to target the five essential elements of reading-phonemic awareness, alphabetic principle, oral reading fluency, vocabulary and comprehension (National Institute of Child Health \& Human Development 2000). Each episode uses explicit systematic instruction and provides numerous opportunities to practice phonics, phonemic awareness, reading vocabulary, reading comprehension, reading fluency-including oral reading, the use of sound elements to decode text, print awareness and deriving meaning from text (Layng et al. 2003, 2004). Each user will hold their own personal profile with private log-in details; thus, the program is entirely individualized to the user and progression through the program is dependent on how quickly or slowly that user acquires each of the curriculum lessons. To reinforce instruction provided in the lessons, HER also provides pupils with read aloud stories and printable books based on the episodes.

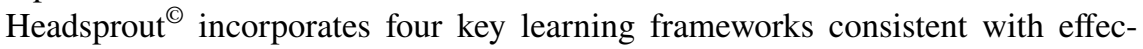
tive and systematic instruction; reduced errors; clear mastery criterion; guided practice; and cumulative review and application. The program meets the NRP's (2000) guidelines for evidence-based instruction in early reading, and a growing body of literature has demonstrated that HER produces positive results in improving literacy skills of individuals with ADHD, autism and typically developing learners, within classroom and home-based settings (Clarfield and Stoner 2005; Grindle et al. 2013; Huffstetter et al. 2010; Layng et al. 2003, 2004; Tyler et al. 2015; Whitcomb et al. 2011). In addition, the computer-based delivery of the program does not place additional pressure on staffing levels, time or resources, as one staff member can act as a program facilitator for small group instruction.

Despite evidence suggesting the cost-effectiveness and efficacy of CAI, many schools in Northern Ireland continue to adopt alternative approaches to supplement the general classroom instruction of struggling readers. Inclusive in these approaches are Reciprocal Reading (Palincsar and Brown 1984), Jolly Phonics (Lloyd and Wernham 2005), Guided Reading (Fountas and Pinnell 1996) and teacher-designed word recognition tasks. This additional support is delivered by a school's Special Education Needs Coordinator (SENCO). SENCO-delivered instruction is intensive, 1:1 support delivered on a daily basis to children who have achieved below average scores on standardized classroom literacy tests (Rose 2009). The effectiveness of this supplementary support in improving pupil progress has been found to be variable (Education Endowment Foundation 2015; Webster et al. 2013). Findings from the Department of Education's (2014) literacy reports suggests that there is no clearly defined curriculum which must be delivered by SENCOs. Instead, an eclectic approach is adopted whereby the instruction delivered is specific to where deficits in scores lie for each child. The extent to which this instruction is systematic is largely unknown. For the school involved in this study, a typical SENCO-delivered session could be made up of 15 min of phonics training, $10 \mathrm{~min}$ of guided reading and $5 \mathrm{~min}$ of sight word training. However, this changed 
weekly and often daily; therefore, the exact nature of what comprised a SENCOdelivered session could not be reported fully and will be referred to here as an eclectic approach to intervention.

Due to high numbers of children failing to reach the lowest literacy benchmark in Northern Ireland, the primary aim of this study is to form the foundation of an evidence base to support systematic CAI approaches to literacy instruction for struggling readers. This aim will be pursued through the direct comparison of the Headsprout ${ }^{\odot}$ Early Reading (HER) program with an eclectic, SENCO-delivered approach to instruction. The following research question will be addressed: Are measures of word/ non-word recognition, sentence reading score (SRS) and Dolch sight words significantly improved through a program of Headsprout ${ }^{\circledR}$ lessons compared with SENCO instruction?

\section{Method}

\section{Participants and Design}

All participants (34 children, ages from 6 to 9 years) attended a primary school where percentages of children receiving free school meals (46.4\%) and SEN support (33\%) had steadily increased over the past 4 years. Inclusion criteria were: (1) no known diagnoses of developmental disorders, including but not limited to, autism, ADHD, ADD or dyslexia; (2) in receipt of free school meals (FSN); (3) ability to attend to a computer for short periods of time; (4) English as first language; (5) capable of understanding/completing two-step instructions; (6) ability to imitate spoken words and sounds; (7) a pre-treatment phonological awareness score lower than the recommended score for their chronological age; (8) in receipt of supplementary literacy support from the school SENCO. The study adopted a between-subjects experimental control design. Children who met all the inclusion criteria were assigned numerical ID's and randomly assigned using an excel number generator to a Headsprout ${ }^{\circledR}$ Early Reading (HER) group ( $n=17)$ or Treatment as usual (TAU) group $(n=17)$ who would continue with their SENCO-delivered literacy instruction. There was some attrition in the TAU group (2 students) due to a school transfer and a parent's decision to remove their child from the study (for TAU, $n=15$ ); therefore, a total of 32 children's scores were analyzed. While the sample size was less than indicated by power analysis, this was the largest number that could be recruited from the school, and including further schools would have introduced other sources of variance.

\section{Setting and Materials}

\section{HER Group}

For each session, children sat in front of a laptop computer (HP Elitebook 8440p) with a mouse and wore soundproof headphones (Sony MDR-XB55OAP). Internet access was essential in order to complete every session. Feedback was provided by 
HER in the form of electronic "gold coins" which could be traded for access to a range of computer games after each episode was completed. Accompanying materials used included printable Sprout Stories and Sprout Cards for fluency building. Sessions took place in a combined computer suite and library within the main school building.

\section{TAU Group}

Materials for the TAU group included SENCO-designed worksheets, the student's current classroom reading book and SENCO-designed laminated word flashcards. Sessions took place in the SENCO's private classroom.

\section{Measures}

For all children who met the inclusion criteria, pre-treatment scores were obtained for word/non-word recognition and sentence reading standardized score (SRS) using the Phonics and Early Reading Assessment (PERA) (McCarty and Ruttle 2012). PERA's Test 1, forms A (pretest assessment) and B (posttest assessment) were constructed to match the experience children will have gained following 3-5 terms of phonics instruction. Test 2 , forms $\mathrm{A}$ and $\mathrm{B}$ were constructed to match the experience of 5 to 7 terms of instruction. All forms were reviewed by early reading experts and, following review, all were standardized in 2011 across England, Wales and Northern Ireland. As such, Test 1 and Test 2 are reported to validly assess the curriculum that most Foundation stage and Key 1 stage teachers follow. A test of reliability was conducted by correlating children's scores on separate forms A and B, 2 weeks apart, and expressed as a Pearson coefficient. All were within the range of 0.88-0.92. Following consultation with classroom teachers of the student participants, and assessment with the PERA's non-standardized pre-phonics assessment tool, it was concluded that all participants would be assessed using Test 2 . The theoretical average standardized score is 100 , and the average range is $85-115$. Children with scores below 85 are considered below average readers who require intervention. The word/ non-word recognition assessment presents a range of real words and nonsense words on a brightly colored flashcard. Correct pronunciation of either the real word or a correct attempt at the phonemes which form the nonsense word are marked as correct responses. There are 20 words per side of an A4 flashcard, and there is no time limit on this assessment. Prior to beginning the assessment, the PERA advises that children are told "Now I am going to point to some words on this page. If you know them, great! If you don't, you can tell me 'I don't know' and we can move to the next word." The sentence reading score assessment is administered similarly. Children are required to read six sentences in total (three from each side of an A4 flashcard), and each correctly read word is given a score. There is no time limit on the assessment; however, if the child incurs five consecutive errors the assessment should be terminated. 
The Dolch words assessment was also administered to provide a measure of each child's awareness of sight words. This assessment contains 220 high-frequency words that cannot be sounded out using common phonics patterns but are necessary to achieve reading fluency. While the Dolch words assessment is free and used by classroom teachers as a screening tool for reading difficulty, it should be used in combination with a standardized assessment. The Dolch words assessment was administered during the pre-treatment assessment and after every 20 HER episodes using Grade lists 1 and 2, and words were presented in random order during every assessment probe.

A self-made social validity questionnaire was designed to assess the perceived effects of Headsprout ${ }^{\circledR}$ on children's reading ability, the feasibility of adopting the program, perceived changes in children's attitudes to reading following the use of the program and knowledge and interest in learning more about programs such as Headsprout. The questionnaire was comprised of 12 statements, and classroom teachers were asked to indicate their level of agreement or disagreement with each of these statements using a 5-point Likert scale. Respondents were afforded the opportunity to provide additional written comments if they felt this was necessary.

\section{Procedure}

Over the course of the study, children in the HER treatment group did not receive supplementary support from their SENCO as they had done up until this point. Children in the TAU group continued with their daily SENCO-delivered instruction, and both groups continued with their daily classroom literacy instruction. TAU sessions varied in their content daily and across each student; therefore, exact reporting on what took place within these sessions was not possible. The school SENCO reported that within each session, decision making was based around ensuring inclusion of phonics training using Jolly Phonics (Lloyd and Wernham 2005), SENCO-designed word recognition tasks and sentence reading using the student's current classroom reading book. Children in the TAU group received one-on-one sessions with the SENCO for 30 min each day from Monday to Friday over a 7-month period (excluding school holidays).

HER sessions ran 5 times per week (Monday to Friday) over a 7-month period (excluding school holidays), and each session lasted for 30 min where children were expected to complete one full episode of HER. Children in the treatment group were brought to the reading resource room in groups of 3 to 5. After logging on to their own personal profile on the Headsprout ${ }^{\circledR}$ home page, they completed an episode and read out loud from the corresponding Sprout Story. Episode 0 of the program, "Mousing Around," ensured that all participants in this group had the necessary prerequisite computer skills to operate the program. Researchers interacted with the children only to assist with computer difficulties and to listen to children independently read their Sprout Stories at the end of each episode. In the event that children did not complete their full episode, they began their session the following day $5 \mathrm{~min}$ earlier than normal, in order to complete the previous day's episode. This occurred a total of 8 times over the duration of the intervention. 
Fluency building materials were used with 3 students for whom progress on the Headsprout $^{\odot}$ episodes was slow, failure to reach $95 \%$ mastery on an episode after 2 attempts. An average of 16 fluency building sessions were conducted for each of these three students throughout the 7-month intervention period.

The study ended after 28 weeks when the school year ended. Post-treatment assessments were then conducted with children in both groups to obtain PERA word/non-word recognition, SRS and Dolch words scores. At this point, staff were asked to complete the social validity questionnaire and provide any additional written comments.

\section{Inter-Observer Agreement (IOA)}

An independent third-party observed and recorded student responses during all pre- and post-treatment assessments. IOA was calculated by dividing the number of observer agreements by the number of judgments. IOA was above $98 \%$ for all pre- and post-treatment assessments. No formal review of procedural integrity was carried out.

\section{Data Analysis}

As there were two independent groups of participants given three measures before and after the Headsprout ${ }^{\odot}$ training, a mixed ANOVA was carried out using SPSS version 24 . Where an effect of treatment was found, post hoc independent samples $t$ tests were used to analyze the changes from pre- to post-treatment.

\section{Results}

Research Question: Are measures of word/non-word recognition, sentence reading score (SRS) and Dolch sight words significantly improved through a program of Headsprout $^{\circledR}$ lessons compared with SENCO instruction?

Table 1 Mean pre- and posttest assessment scores and standard deviations (in brackets) for intervention and treatment as usual groups, with ANOVA $F$ values, associated $p$ values and effect sizes

\begin{tabular}{|c|c|c|c|c|c|c|c|}
\hline & \multicolumn{2}{|c|}{$\begin{array}{l}\text { Headsprout early reading } \\
\text { (HER) }\end{array}$} & \multicolumn{2}{|c|}{ Treatment as usual (TAU) } & \multicolumn{3}{|l|}{ ANOVA } \\
\hline & Pretest & Posttest & Pretest & Posttest & & & \\
\hline & $M(\mathrm{SD})$ & $M(\mathrm{SD})$ & $M(\mathrm{SD})$ & $M(\mathrm{SD})$ & $\mathrm{F}(1,30)$ & $p$ & $d$ \\
\hline $\begin{array}{l}\text { Word/non-word } \\
\text { recognition }\end{array}$ & $74.88(4.44)$ & $99.41(7.13)$ & $73.53(5.34)$ & $78.27(8.70)$ & 55.14 & 0.0001 & 2.65 \\
\hline Sentence reading & $81.82(3.63)$ & $97.53(8.64)$ & $81.33(5.12)$ & $88.67(9.85)$ & 14.44 & 0.002 & 0.96 \\
\hline Dolch words & $17.4(16.37)$ & $65.8(34.6)$ & $8.9(15.31)$ & $23.4(18.5)$ & 8.26 & 0.0001 & 1.53 \\
\hline
\end{tabular}


Mean scores for the three measures of reading attainment, word/non-word recognition, SRS and Dolch words at pre- and post-treatment for both groups are shown in Table 1. At pre-treatment, both groups had similar scores on each measure $(t=0.78$, $t=0.32$ and $t=1.5$, for word/non-word recognition, SRS and Dolch word scores respectively; $p>0.05$ in each case). With treatment, there was a main effect of group on each measure, as shown in Table 1, with the HER group having higher scores in each case $(t=7.55, t=3.33$ and $t=4.23$ for word/non-word recognition, SRS and Dolch word scores, respectively; $p<0.01$ in each case). Effect sizes were based on Cohen's $d$ and were calculated using the mean change scores for both groups and the pooled standard deviations. As indicated in Table 1, these were 0.96, 1.53 and 2.65, a range interpreted as indicative of large effect sizes. Figure 1 displays the difference in sight word acquisition for both groups. Data for the HER group show a marked upward trend, while the TAU group's scores increase slightly and erratically. We can therefore answer the research question in the affirmative.

The social validity questionnaire completed by eight teachers revealed that the response to HER being used in the school was generally positive. Six out of eight teachers indicated that they would consider using Headsprout ${ }^{\odot}$ again, and that they were glad they had had the opportunity to learn about it and that more educators should have the opportunity to learn about this and similar programs. While six out of eight teachers indicated that students enjoyed using Headsprout and looked forward to their sessions, staff were less sure about the actual effects on reading that

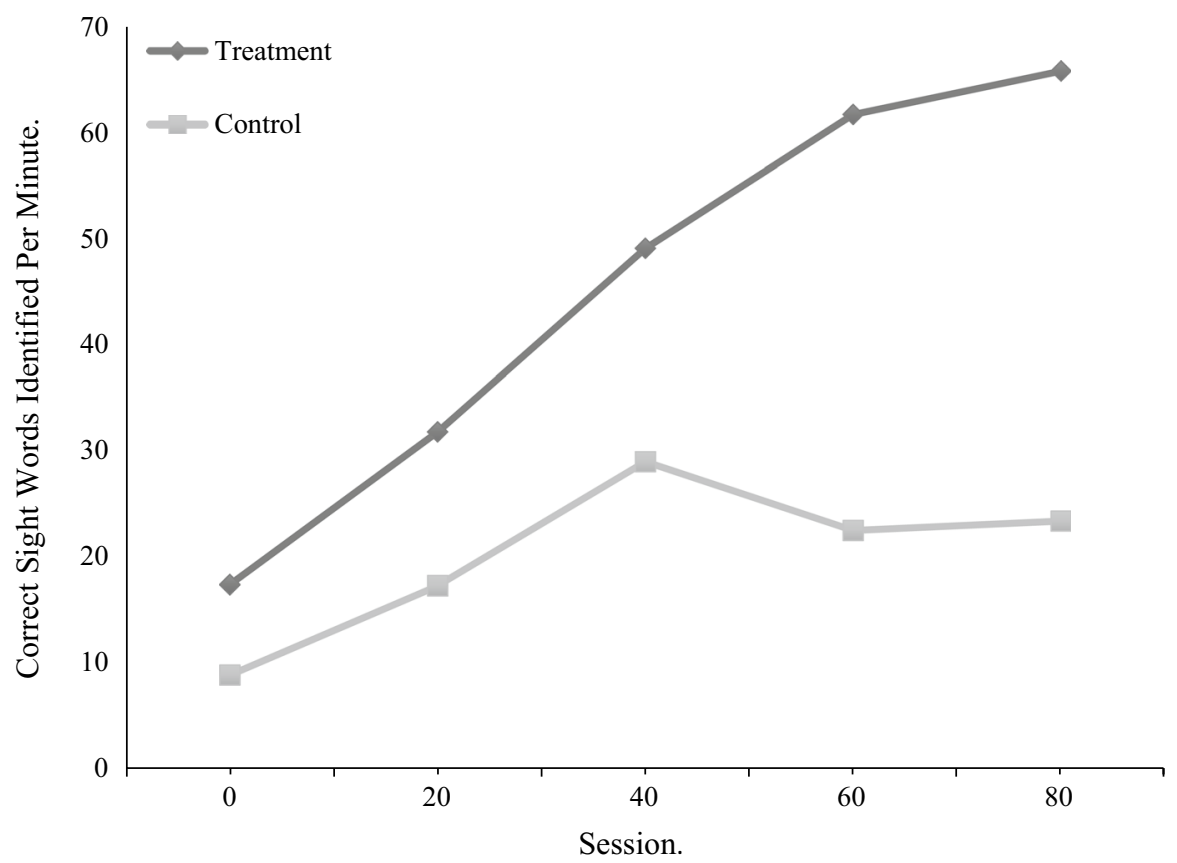

Fig. 1 Dolch word mean scores for the two groups measured at the outset and after completion of each block of 20 sessions 
the program had: three respondents agreed that Headsprout promoted independent reading, positive attitudes to reading and aided student learning, leaving five who were "not sure." Qualitative data in the form of written comments solicited from staff indicated that they would have been more certain of the effects of Headsprout on student reading had they seen actual data generated by the program itself. Comments included the following: "Impossible to answer question 1 and 2 as we have not seen data from the program. In-house monitoring shows Y2 have made some added progress and Y3 made a lot, but I would prefer to see formal data" and "Student improvement is difficult to judge until we get scores. However, from class assessments etc. it appears that the children are moving forward with their learning."

\section{Discussion}

The primary aim of this study was to form the foundation of an evidence base to support systematic CAI approaches to literacy instruction for struggling readers through the direct comparison of the Headsprout ${ }^{\circledR}$ Early Reading (HER) program with an eclectic, SENCO-delivered approach to instruction (treatment as usual for struggling readers). Results demonstrated that children receiving HER intervention for specific literacy difficulties gained significantly higher post-treatment scores in measures of word/non-word recognition and sentence reading than those in the TAU group. Children in the HER treatment group also displayed greater improvements over the duration of the study in their knowledge of high-frequency words as measured by the Dolch word assessment. The HER treatment group experienced a significant and substantial improvement of 48.4 words from pre-intervention to postintervention on this measure in comparison with the TAU group. This study adds to a growing body of the literature that demonstrates the positive effects of HER on children's literacy skills, when delivered either as one-to-one, small group or classroom-based programs (Grindle et al. 2013; Huffstetter et al. 2010; Layng et al. 2003, 2004; Storey et al. 2017; Tyler et al. 2015).

Considering the changes in mean scores across groups from pre- to post-intervention, it is unsurprising that both HER and TAU groups experienced increases in standardized scores from pre- to post-treatment, especially given that the TAU group in this instance were receiving supplementary literacy provision from the school SENCO throughout the duration of the study. However, in the word/non-word recognition measure the HER group increased their mean pre-intervention score of 74.88 to 99.41 while the TAU group demonstrated only a small increase from 73.53 to 78.27. Similarly, in measures of sentence reading, the HER group experienced a significant increase in their pre-intervention score from 81.82 to 97.53 while the TAU group experienced a nonsignificant increase from 81.33 at pre-intervention to 88.67 at post-intervention. As both groups of children were receiving supplementary support outside of the classroom (from either the school SENCO or the researchers), for the same duration each day, the larger improvements for the HER group cannot simply be attributed to increased contact with adults. This finding demonstrates that although an eclectic approach to literacy intervention (as was the case with the TAU group) may be somewhat effective, it does not result in the same 
degree of improvement as a CAI-delivered, systematic phonics approach to literacy instruction.

Rose (2009) suggested that an effective intervention should quicken the pace of learning in an attempt to close the gap between those with specific literacy difficulty and their peers. Therefore, these results raise a concern that SENCO-delivered literacy instruction may not be closing the attainment gap. It is evident from this research that the one-to-one provision provided by SENCO's may increase literacy attainment scores slowly and slightly but may not be providing the intensive support needed to get these children to where they need to be in order to achieve the expected levels set out in the National Curriculum. In addition, through the use of an eclectic approach to instruction, it is difficult to determine the contributing factor to this slow but slight increase in attainment. Thus, evaluative studies on SENCO-delivered literacy instruction in Northern Irish Schools should be explored in order to understand more about the exact type of intervention provided within these sessions.

The use of Headsprout ${ }^{\odot}$ may also benefit schools with regard to cost-effectiveness. A systematic, one-to-one approach for each child who requires literacy support may often be too expensive or require resources that are not available consistently (Elbaum et al. 2000). However, in this study, 30-min interaction with the Headsprout $^{\circledR}$ computer in groups of up to 5 other children with a maximum of 2 facilitators produced significantly better outcomes for children with specific literacy difficulty than 30-min one-to-one with a SENCO adopting an eclectic approach to instruction. This finding supports the research from Hall et al. (2000), who stated that CAI-based supplementary instruction produces faster learning and better gains than conventional instruction alone. One implication of these findings is that it could potentially be more cost-effective for resources that are currently allocated to planning and implementing SENCO sessions to be transferred to staff training in delivering evidence-based approaches such as Headsprout ${ }^{\circ}$ in a small group settings.

Findings from this study emphasize that a non-systematic approach to literacy instruction and that which deviates from the National Reading Panel's guidelines may not be resulting in large enough improvements for struggling readers to close the attainment gap. CAI approaches to literacy instruction provide a solution to the difficulties which may be faced by SENCO's and classroom teachers in creating a systematic approach to instruction for the large number of children who need it. A systematic approach to instruction requires constant monitoring and evaluation in order to make data-driven decisions which in practice require that SENCO's engage in more formal testing than what is mandatory; however, limited resources render this extremely difficult. CAI programs such as Headsprout ${ }^{\circledR}$ provide this monitoring and evaluation within the program and require little teacher involvement; therefore, resources can be reallocated to additional areas of need within the classroom.

Despite promising outcomes demonstrated by the findings, there are limitations which need to be addressed. This school did not provide the researcher with a clear literacy curriculum followed by the SENCO in addressing specific literacy disorder. Rather, the researcher had to rely on anecdotal evidence from the SENCO regarding what took place within the sessions (e.g., "some phonics training, high-frequency word recognition tasks and sentence reading"); therefore, it could be argued that it is not clear which teaching strategies Headsprout ${ }^{\circledR}$ has been compared with in this 
instance. Although assessment data or mastery criteria were not provided by the SENCO, it cannot be stated with certainty that the sessions provided in this instance were not following a systematic method of instruction (Singleton 2009). However, they may have been based on whole-language approaches to literacy instruction, which are already known to be relatively ineffective with at-risk learners. To provide a fairer test of conventional SENCO-led instruction versus Headsprout ${ }^{\circledR}$ used in small groups, future research should evaluate its components and relative efficacy across a school district rather than in a single school as in the present study.

Despite these limitations, this study provides preliminary evidence that the use of CAI in Northern Irish primary schools presents a solution to the high numbers of children failing to reach expected literacy levels by the time they leave primary school. In addition, these findings provide evidence of a more cost-effective way in which to provide support for these growing numbers.

\section{Compliance with Ethical Standards}

Conflict of interest The authors declare that they have no conflict of interest.

Ethical Approval All procedures performed in studies involving human participants were in accordance with the ethical standards of the Ulster University Research Ethics Committee and with the 1964 Helsinki declaration and its later amendments or comparable ethical standards.

Informed Consent Informed consent was obtained from all individual participants included in the study.

Open Access This article is distributed under the terms of the Creative Commons Attribution 4.0 International License (http://creativecommons.org/licenses/by/4.0/), which permits unrestricted use, distribution, and reproduction in any medium, provided you give appropriate credit to the original author(s) and the source, provide a link to the Creative Commons license, and indicate if changes were made.

\section{References}

Bradley, L., \& Bryant, P. (1983). Categorizing sounds and Learning to Read: A causal connection. Nature, 301, 419-421.

Carter, M., \& Wheldall, K. (2008). Why can't a teacher be more like a scientist? Science, Pseudoscience and the art of teaching. Australasian Journal of Special Education, 32(1), 2-5.

Clarfield, J., \& Stoner, G. (2005). The effects of computerized reading instruction on the academic performance of students identified with ADHD. School Psychology Review, 34(2), 246-254.

Clay, M. M. (1987). Implementing reading recovery: Systematic adaptions to an educational innovation. New Zealand Journal of Educational Studies, 22, 35-58.

Clipson-Boyles, S. (2000). The catch up project: a reading intervention in year 3 for level 1 readers (research note). Journal of Research in Reading, 23(1), 78-84.

Cotton, K. (1991). Computer-assisted instruction. Northwest Regional Educational Laboratory School Improvement Research Series (SIRS). Retrieved April 20, 2015 from https://www.nwrel.org/scpd/ sirs/5/cu10.html.

Department for Education. (2014). Influences on students' GCSE attainment and progress at age 16. Effective Pre-School, Primary \& Secondary Education Project (EPPSE) Research Report. Retrieved February 10, 2015 from https://dera.ioe.ac.uk/20875/1/RR352. 
Education Endowment Foundation Toolkit. (2015). Parental engagement. Early Years Toolkit. Retrieved February 10, 2015 from https://educationendowmentfoundation.org.uk/evidence/early-years-toolk it/.

Elbaum, B., Vaughn, S., Hughes, T., \& Moody, S. (2000). How effective are one-to-one tutoring programs in reading for elementary students at risk for reading failure? A meta-analysis of the intervention research. Journal of Educational Psychology, 92(4), 605-619.

Fountas, I. C., \& Pinnell, G. S. (1996). Guided reading: Good first teaching for all children. Portsmouth, NH: Heinemann.

Grindle, C. F., Hughes, C. J., Saville, M., Huxley, K., \& Hastings, R. P. (2013). Teaching early reading skills to children with autism using Mimiosprout early reading. Behavioral Interventions, 28(3), 203-224.

Hall, T. E., Hughes, C. A., \& Filbert, M. (2000). Computer assisted instruction in reading for students with learning disabilities: A research synthesis. Education and Treatment of Children, 23, 173-193.

Hatcher, P. J., Hulme, C., \& Ellis, A. W. (1994). Ameliorating early reading failure by integrating the teaching of reading and phonological skills: The phonological linkage hypothesis. Child Development, 65(1), 41-57.

Huffstetter, M., King, J. R., Onwuegbuzie, A. J., Schneider, J. J., \& Powell-Smith, K. A. (2010). Effects of a computer-based early reading program on the early reading and oral language skills of at-risk preschool children. Journal of Education for Students Placed at Risk, 15(4), 279-298.

Johnston, R. S., \& Watson, J. E. (2004). Accelerating the development of reading, spelling and phonemic awareness skills in initial readers. Reading and Writing, 17(4), 327-357.

Joseph Rowntree Foundation. (2012). Tackling low educational achievement. London: Joseph Rowntree Foundation.

Karemaker, A., Pitchford, N. J., \& O'Malley, C. (2010). Enhanced recognition of written words and enjoyment of reading in struggling beginner readers through whole-word multimedia software. Computers \& Education, 54(1), 199-208.

Lane, C. (2010). The A.R.R.O.W approach for the improvement of literacy and communication skills. Retrieved March 15, 2015 from http://www.learning-works.org.uk/arrow-article-pdf.

Layng, J., Twyman, J., \& Stikeleather, G. (2003). Headsprout early reading: Reliably teaching children to read. Behavioral Technology Today, 3, 7-20.

Layng, J., Twyman, J., \& Stikeleather, G. (2004). Selected for success: How Headsprout reading basics teaches beginning reading. In D. J. Moran \& R. W. Malott (Eds.), Evidence-based educational methods (pp. 171-197). San Diego: Elsevier Academic Press.

Linehan, C., Kirman, B., Lawson, S., \& Chan, G. (2011). Practical, appropriate, empirically-validated guidelines for designing educational games. In Proceedings of the 2011 annual conference on Human factors in computing systems. New York: CHI'11.

Lloyd, S., \& Wernham, S. (2005). Jolly stories in print letters. Chigwell, Essex: Jolly Learning.

Lundberg, I., Frost, J., \& Peterson, O. (1998). Effects of an extensive program for stimulating phonological awareness in preschool children. Reading Research Quarterly, 23, 263-285.

Macaruso, P., Hook, P. E., \& McCabe, R. (2006). The efficacy of computer-based supplementary phonics programs for advancing reading skills in at-risk elementary students. Journal of Research in Reading, 29, 162-172.

Macaruso, P., \& Walker, A. (2008). The Efficacy of computer-assisted instruction for advancing literacy skills in kindergarten children. Reading Psychology, 29(3), 266-287.

McCarty, C., \& Ruttle, K. (2012). Phonics \& early reading assessment: for reception, years 1 and 2. London: Hodder Education.

McIntosh, S., \& Vignoles, A. (2001). Micro-analysis of the effects of literacy and numeracy. In J. Bynner, et al. (Eds.), Improving adult basic skills: Benefits to the individual and to society. London: Centre for Longitudinal Studies.

Morgan, R. T. (1976). Paired reading tuition: A preliminary report on a technique for cases of reading deficit. Child: Care, Health and Development, 2(1), 13-28.

National Institute of Child Health \& Human Development. (2000). Report of the National Reading Panel: Teaching children to read: An evidence-based assessment of the scientific research literature on reading and its implications for reading instruction. (NIH Publication No. 00 4769). Washington, DC: U.S. Government Printing Office.

National Reading Panel. (2000). Report of the national reading panel: Teaching children to read: An evidence-based assessment of the scientific research literature on reading and its implications for 
reading instruction: Reports of the subgroups. Bethesda, MD: National Institute of Child Health and Human Development, National Institutes of Health.

Northern Ireland Executive. (2000). Programme for Government Consultation Document, 2000. Retrieved April 2018 from https://www.northernireland.gov.uk/sites/default/files/consultations/ newnigov/pfg-consulation-document.PDF

Ornstein, A. C., \& Levine, D. U. (1993). Foundations of educations (5th ed.). Boston: Houghton Mifflin Co.

Palincsar, A. S., \& Brown, A. L. (1984). Reciprocal teaching of comprehension fostering and comprehension-monitoring activities. Cognition and Instruction, 1(2), 117-175.

Rose, R. (2009). Identifying and teaching children and young people with dyslexia and literacy difficulties. The Dyslexia SPLD Trust. Retrieved August 6, 2016 from http://www.thedyslexiaspldtrust.org. uk/media/downloads/inline/the-rosereport.1294933674.pdf.

Save the Children. (2015). Reaching every last child. Retrieved February 9, 2016 from Save the children website https://www.savethechildren.org.uk/content/dam/global/reports/annual-report-2015.pdf.

Sedega, C. S., Mishiwo, M., Fletcher, J. A., Kofi, G. A., \& Awudetsey, J. (2017). Effect of computer assisted instruction on senior high school students achievement at pie chart and histogram in core mathematics. British Journal of Education, 5(9), 45-68.

Singleton, C. (2009). Intervention for dyslexia. A review of published evidence on the impact of specialist dyslexia teaching. Retrieved March 14, 2015 from http://www.4d.org.nz/school/dyslexia_interventi on_research.pdf.

Stetter, M. E., \& Hughes, M. T. (2010). Computer assisted instruction to enhance reading comprehension of struggling readers: A review of the literature. Journal of Special Education Technology, 25(4), $1-16$.

Storey, C., McDowell, C., \& Leslie, J. (2017). Evaluating the efficacy of the Headsprout reading program with children who have spent time in care. Behavioral Interventions, 32(3), 285-293. https://doi. org/10.1002/bin.1476

Tyler, E. J., Hughes, J. C., Beverley, M., \& Hastings, R. P. (2015). Improving early reading skills for beginning readers using an online programme as supplementary instruction. European Journal of Psychology of Education, 30(3), 281-294.

Watkins, C. L. (1997). Project follow through: A case study of contingencies influencing instructional practices of the educational establishment. Cambridge, MA: Cambridge Center for Behavioral Studies.

Webster, R., Blatchford, P., \& Russell, A. (2013). Challenging and changing how schools use teaching assistants: Findings from the effective deployment of teaching assistants project. School Leadership and Management, 33(1), 78-96.

Whitcomb, S. A., Bass, J. D., \& Luiselli, J. K. (2011). Effects of a computer-based early reading program $\left(\right.$ Headsprout $\left.^{\circledR}\right)$ on word list and text reading skills in a student with autism. Journal of Developmental and Physical Disabilities, 23(6), 491-499.

Publisher's Note Springer Nature remains neutral with regard to jurisdictional claims in published maps and institutional affiliations. 